\title{
Stability of Ampelometric Characteristics of Vitis vinifera L. cv. 'Syrah' and 'Sauvignon blanc' Leaves: Impact of Within-vineyard Variability and Pruning Method/Bud Load
}

\author{
P. Bodor ${ }^{1}$, L. Baranyai ${ }^{2}$, M. Ladányi ${ }^{3}$, B. Bálo ${ }^{4}$, A.E. Strever ${ }^{5}$, Gy.D. Bisztray ${ }^{1 *}$, J.J. Hunter ${ }^{5,6^{*}}$ \\ (1) Department of Viticulture, Institute of Viticulture and Oenology, Corvinus University of Budapest, 29-43 Villányi Street, \\ H-1118 Budapest, Hungary \\ (2) Department of Physics and Automatization, Faculty of Food Sciences, Corvinus University of Budapest, 14-16 Somlói \\ Street, H-1118 Budapest, Hungary \\ (3) Department of Mathematics, Faculty of Horticultural Sciences, Corvinus University of Budapest, 29-43 Villányi Street, \\ H-1118 Budapest, Hungary \\ (4) Róbert Károly College, Research Institute of Viticulture and Enology, Kőlyuktető Pf.: 83. Eger, H-3300, Hungary \\ (5) Department of Viticulture and Oenology, Stellenbosch University, Private Bag X1, Matieland, 7602, Stellenbosch, South \\ Africa \\ (6) ARC Infruitec-Nietvoorbij ${ }^{1}$, Private Bag X5026, 7599, Stellenbosch, South Africa
}

Date submitted for publication: October 2012

Date accepted for publication: March 2013

Key words: foliometry, grapevine, leaves, variability, pruning

\begin{abstract}
Historically, grapevine (Vitis vinifera $\mathrm{L}$.) leaf characterisation has been a driving force in the identification of cultivars. In this study, ampelometric (foliometric) analysis was done on leaf samples collected from hand-pruned, mechanically pruned and minimally pruned 'Sauvignon blanc' and 'Syrah' vines to estimate the impact of within-vineyard variability and a change in bud load on the stability of leaf properties. The results showed that within-vineyard variability of ampelometric characteristics was high within a cultivar, irrespective of bud load. In terms of the O.I.V. coding system, zero to four class differences were observed between minimum and maximum values of each characteristic. The value of variability of each characteristic was different between the three levels of bud load and the two cultivars. With respect to bud load, the number of shoots per vine had a significant effect on the characteristics of the leaf laminae. Single leaf area and lengths of veins changed significantly for both cultivars, irrespective of treatment, while angle between veins proved to be a stable characteristic. A large number of biometric data can be recorded on a single leaf; the data measured on several leaves, however, are not necessarily unique for a specific cultivar. The leaf characteristics analysed in this study can be divided into two groups according to the response to a change in bud load, i.e. stable (angles between the veins, depths of sinuses) and variable (length of the veins, length of the petiole, single leaf area). The variable characteristics are not recommended to be used in cultivar identification, unless the pruning method/bud load is known.
\end{abstract}

\section{INTRODUCTION}

Worldwide, up to 15000 grapevine cultivars are grown. The characterisation of each of these cultivars has high importance for preservation and propagation. The morphological identification of Vitis taxa is called ampelography. This term was mentioned for the first time in the middle of the $17^{\text {th }}$ century (Viala \& Vermorel, 1910), although it dates back to ancient times (Pliny the Elder, 1855). Together with molecular genetic and chemotaxonomic characterisation, it still is an important method in the description of cultivars today (Zulini et al., 2005; Gago et al., 2009). Morphological identification should be the first step in a standard protocol for the characterisation and documentation of single plants, and even for the establishment of a germplasm collection (Ortiz et al., 2004), in order to avoid misnomers (Galet, 1956) and synonymy (González et al., 2007). Phenotypical

\footnotetext{
${ }^{1}$ The Fruit, Vine and Wine Institute of the Agricultural Research Council

*Corresponding authors: Gy.D. Bisztray; E-mail: gyorgy.bisztray@uni-corvinus [Tel.: +361 4826283; Fax: +3614664650], J.J. Hunter; E-mail: Hunterk@arc.agric.za [Tel.:+27-21-809 3057; Fax +27-21-809 3002]

Aknowledgements: The authors would like to thank the South African Wine Industry (Winetech), for funding of the project. We gratefully acknowledge the technical management of the vineyard by D. van Schalkwyk and A. Schmidt of the Viticulture Department of ARC Infruitec-Nietvoorbij. The authors also thank Konrad Pixner, for assistance during the sampling. This project was also supported by the Hungarian-South-African bilateral agreement ZA-23/07
} 
descriptions of cultivars are based on the characterisation of organs, such as roots, canes, buds, shoots, leaves, tendrils, fruits, seeds and trichomes, according to the International Organisation of Vine and Wine (O.I.V., 2009a). It should be noted that not only environmental factors, such as soil properties (Ferree \& Streeter, 2004), water availability (Reynolds \& Naylor, 1994) and salinity (Fisarakis et al., 2001), but also the rootstock (Krstic et al., 2005), nutritional status (Schreiner et al., 2012) and health of the plant may have significant effects on morphological patterns (Cervera et al., 2001).

The grapevine leaf is an extremely variable organ. The shape (predominantly palmate) and size of the leaf depends on the number of lobes, the length of the veins and the depth of the sinuses. Almost all cultivars have individual shapes of lamina, which present the possibility of identification (Mullins et al., 2003). Metric analyses of certain parameters of the leaf are called ampelometry. There are almost 50 biometric descriptors related to the mature leaf, e.g. size of the lamina, angles between the veins, lengths of veins, etc. The ampelometric parameters of the cultivars are available in the literature (Németh, 1966, 1967, 1970; Goussard, 2008) and "on-line", such as in the European Vitis Database (Maul et al., 2012). Ortiz et al. (2004) classified leaf characteristics into three groups, namely stable or objective characteristics, discriminant and non-discriminant characteristics. Sefc et al. (2001) reported that morphological identification could be influenced by interpretation. Digital image analysis could support ampelometric descriptions with time-efficient and objective measurements, which exclude arbitrary decisions. Software environments like Ampelocad (Alessandri et al., 1996), Digital Image Processing System MIP 1.4 (MICROM) (Martinez \& Mantilla, 1995) and SuperAmpelo (Soldavini et al., 2009), as well as outline data analysis of the lamina (Kondou et al., 2002), are suitable for the digital reconstruction and characterisation of grapevine leaves. Our previous results proved that ampelometry in a raster-graphic environment is a powerful tool for the digital analysis and characterisation of grapevine leaves (Bodor et al., 2012).

The concept of within-vineyard variability is not new (Bramley \& Hamilton, 2004; Hunter et al., 2010). Its effect on yield and quality is well known and can be observed between and within vines (Rolley et al., 2007). The description of the cultivars given by the O.I.V. also considers this type of variability of each cultivar, as in the case of 'Sauvignon blanc' leaves, where the 'Length of teeth compared with their width' (O.I.V. 078) is "short" (Nr. 3) to "medium" (Nr. 5), but other properties are also variable, such as the "Mature leaf: degree of opening / overlapping of petiole sinus' (O.I.V. 079), and the 'Mature leaf: degree of opening / overlapping of upper lateral sinuses' (O.I.V. 082, etc.). This variability has also been observed in the case of 'Syrah' (O.I.V., 2009b).

Within ampelometric characterisation, the size of the leaf blade (single leaf area - SLA) is a crucial parameter, as it determines photosynthetic activity, as affected by the structure of the vine, training and trellising system, microclimate and pruning method (Clingeleffer \& Krake, 1992). Pruning is an integral part of the success of any grapevine trellising system in relation to quantitative and qualitative production. The effect of pruning level on grapevine production and physiology is well known (Intrieri et al., 2011). Detailed observations related to the change in SLA caused by bud load have been reported. For example, Clingeleffer (1984) detected no significant differences in ALA (average leaf area) and LAI (leaf area index) as a result of minimal pruning (MIN) of 'Sultana' vines compared to those subjected to conventional pruning (CP). Sommer et al. (1995) reported reduced SLA and LAI in the case of vines subjected to MIN compared to those collected from conventionally pruned 'Sultana'. Similar observations were reported by Downton and Grant (1992) on 'Riesling' and by Sommer and Clingeleffer (1993) on 'Cabernet Sauvignon'. Both reports showed almost twofold higher SLA in the case of CP compared to MIN. Later, similar results were published on 'Chardonnay' (Poni et al., 2000) and 'Sangiovese' (Intrieri et al., 2001). The lowest level of differences caused by bud load is the variance in SLA as reported by Cangi and Kiliç (2011) on 'Narince'; no significant difference in MLA (mean leaf area) was found with 16 buds/vine compared to 24 buds/ vine. Except for average leaf area, the impact of viticultural practices on the deeper ampelometric description of leaves has not received any attention.

The objective of this study was to estimate withinvineyard variability and to determine the impact of viticulture practices, such as pruning method and therefore bud load/shoot number, on the stability of ampelometric characteristics of two grapevine cultivars.

\section{MATERIALS AND METHODS}

\section{Vineyard}

The experiment was carried out in 2011 on 14-yearold 'Sauvignon blanc' and 'Syrah' vines grown on the experimental farm of ARC Infruitec-Nietvoorbij, situated in the Robertson district of South Africa (Archer \& Van Schalkwyk, 2007). A VSP (vertical shoot positioning) trellising system was used. The vines were spaced at $3.0 \mathrm{~m}$ $\times 1.5 \mathrm{~m}$. Both cultivars were grafted onto Richter $99 \mathrm{RY} 13$ rootstock. No topping or leaf removal practices were applied. Three pruning methods were used and each treatment, carried out in a single row, comprised 44 vines per cultivar:

- hand spur pruned (HAND): 24 to 28 buds/vine

- mechanically pruned (MECH): 63 to 76 buds/vine

- minimally pruned (MIN): 97 to 128 buds/vine.

\section{Sample collection and measurements}

Sample collection and ampelometric observations were made according to the O.I.V. descriptor list (O.I.V., 2009a). Ten mature leaves were collected randomly from the middle third of 10 shoots (one sample/one plant) before harvest (at the end of March 2011). It was assumed that the collected leaves were fully developed at this time.

Characterisation of the leaves was done using 18 O.I.V. characteristics, according to the descriptor list, taking into consideration those characters recommended to be described between berry set and véraison: Mature leaf: size of blade (O.I.V. 065); Mature leaf: length of petiole compared to length of middle vein (O.I.V. 093); Mature leaf: depth of upper lateral sinuses (O.I.V. 094).

During the measurements, two modifications were made compared to the O.I.V. recommendation (signed with $*$ and $* *)$ : 
- Mature leaf: opening/overlapping of lobes on each side of petiole sinus (O.I.V. 618*) was measured according to the distance between the tooth tip of the $\mathrm{N}_{5}$ veins. In the case of overlapping of lobes, values are given as positive numbers, while in the case of an open sinus, values are given as negative numbers.

- Mature leaf: depths of sinuses (O.I.V. 094**) is given in numeric scale as $\mathrm{N} 2-1 / \mathrm{S} 1 ; \mathrm{N} 2-2 / \mathrm{S} 2$; if the value is around 1, it means the sinus was "very shallow" (O.I.V. Nr. 1), while the sinus is deeper as the value increases (O.I.V. Nr. 3-9).

Beside the 18 O.I.V. descriptors, single leaf area (SLA), length of the petiole $(\mathrm{P})$ and depth of the petiole sinus (PS-1; PS-2) were also monitored. Detailed ampelometric dimensions, representing 22 biometric parameters (see Table 1) were recorded for each sample (Fig. 1), using GRA. LE.D. software according to the protocol described in Bodor et al. (2012).

Measured features were coded from 1 to 9 , where 1 to 3 represented shorter, or low, value, and 7 to 9 coded for longer or high values according to the O.I.V. descriptor list (2009a).

\section{Data analysis}

The mean, standard deviation, minimum and maximum were calculated for each treatment and for each cultivar. Statistical analysis MANOVA (multifactorial analysis of variance) was carried out with PASW 18 (release version 18.0.0, SPSS Inc., Chicago, IL, www.spss.com) to test for significant differences between treatments and cultivars. Wilk's $\lambda$ counts the proportion of variance in the combination of the dependent variables that is unaccounted for by the independent variables (fixed factors), such as treatments and cultivars. The lower the Wilk's $\lambda$ values, the stronger the discriminating effects of the factors. The effect size measure (denoted by partial $\eta^{2}$ ), which gives the variance explained by a given independent factor of the variance remaining after excluding variance explained by the other independent factor, was also considered. The higher the partial $\eta^{2}$ values, the stronger the effect sizes (Everitt \& Dunn, 1991). The power of the effect, i.e. the probability of correctly rejecting the $\mathrm{H}_{0}$ hypothesis that assumes the homogeneity of means, is also given. High power values mean that significant results are detected when there are real differences between factor levels. Normality of residuals was checked using the D'Agostino test, with $\mathrm{P}>0.05$ (D'Agostino et al., 1990). With the aim of normalising the distribution of the data, Box-Cox transformations (Box \& Cox 1964) were made in the case of some parameters, such as S-1 $(\lambda=-0.1)$, N2$1 / \mathrm{S}-1(\lambda=-1.4)$, and $\alpha(\lambda=0.3)$. Equality of variances was tested with Levene's test. Depending on the results, Tukey's or Dunnett's post hoc test was applied. Using the main vein as central axis, the symmetry of the leaves was proved with correlation analysis of the opposite pairs $(n=60)$.

\section{Graphic reconstruction}

The graphic reconstructions of the leaves were made by using the datasets obtained from the 10 leaves of each of the two cultivars (Bodor et al., 2012).

\section{RESULTS}

Data obtained from the ampelometric descriptions of the samples are given in Table 1. A two-way MANOVA revealed a significant multivariate main effect for both pruning method [Wilk's $\lambda=0.04 ; \mathrm{F}(46 ; 64)=5.58 ; \mathrm{p}<0.001$; partial eta squared $=0.8$; power to detect the effect was as high as 0.999] and cultivar [Wilk's $\lambda=0.39 ; \mathrm{F}(23 ; 32)$ $=2.2 ; \mathrm{p}<0.05$, partial eta squared $=0.6$; observed power was 0.95$]$. We thus concluded that pruning method/bud load (shoot number) had a significant effect on grapevine leaf characteristics. Foliometric characteristics changed for both the 'Syrah' and 'Sauvignon blanc' cultivars. The interaction was insignificant $(p>0.10)$. Given the significance of the overall test, the univariate main effects were examined. The results of the post hoc tests are given in Table 1.

\section{Within-vineyard variability}

The variability of characteristics within each treatment in each cultivar was analysed by coding the minimum and maximum values of measured properties according to the O.I.V. coding system from 1 to 9 (Table 1). Our observations of within-vineyard variability proved that ampelometric characteristics were highly diverse within 10 collected leaves.

In the case of 'Sauvignon blanc', the lengths of veins, sinuses and petioles showed less variability than those of 'Syrah'. Observations of angles between veins showed that 'Sauvignon blanc' had higher variability than 'Syrah'. According to the results, only length of vein N1 (O.I.V. 601) $(67.72 \mathrm{~mm}$ to $88.8 \mathrm{~mm}=$ "very short") and length of vein N2-1 (O.I.V. 602) (58.49 $\mathrm{mm}$ to $73.96 \mathrm{~mm}=$ "very short") had such a low variability in MIN 'Sauvignon blanc' that it could be categorised into a class of its own. In the case of MIN 'Syrah', only the depth of the upper sinus proved to be stable.

For both cultivars, the opening of the petiole sinus ( $\alpha$; PS1-PS2) proved to be the most variable characteristic. In the case of HAND 'Sauvignon blanc' it varied from $-27.06^{\circ}(+17.95 \mathrm{~mm})$ to $33.14^{\circ}(-15.59 \mathrm{~mm})$ between vines, whereas in the case of HAND 'Syrah' it varied from $-39.25^{\circ}$ $(+29.25 \mathrm{~mm})$ to $28.99^{\circ}(-15.86 \mathrm{~mm})$, which means that there were variations of "open" to "overlapped" petiole sinuses in both cultivars. High variability was also observed in angle $\delta$ for both cultivars.

\section{Effect of bud load on morphological characteristics Single leaf area}

The SLA proved to have the most variable characteristic, significantly decreasing with level of bud load as induced by pruning method. Leaves on the MECH vines were $28 \%$ and those on MIN 59\% smaller than those of the HAND vines (Fig. 2).

\section{Lengths of veins}

In general, the size of a leaf lamina is related to the lengths of the veins (Beslic et al., 2010). Significant differences were recorded in almost all veins, but not to the same extent. Differences between the MIN and MECH datasets were much larger than those between $\mathrm{MECH}$ and HAND. In the case of 'Sauvignon blanc', the veins indicated with N3-1 and 
N3-2 were more sensitive to pruning treatment than other veins. Furthermore, the sectors next to the petiole sinus and the N3-2 and N3-1 veins were the most variable. According to our results, 'Sauvignon blanc' leaves proved to be more sensitive to pruning system/bud load than 'Syrah' leaves (Fig. 2).

\section{Symmetry of leaves}

If the main vein is considered as a central axis, the symmetry of the leaf can be studied. Strong correlations between lengths of veins N2-1 and N2-2 $\left(\mathrm{R}^{2}=0,843\right), \mathrm{N} 3-1$ and N3-2 $\left(\mathrm{R}^{2}=0,900\right), \mathrm{S}-1$ and $\mathrm{S}-2\left(\mathrm{R}^{2}=0,821\right)$, and PS-1 and PS-2 $\left(R^{2}=0,885\right)$ were found $(n=60, p<0,001)$. Similar results

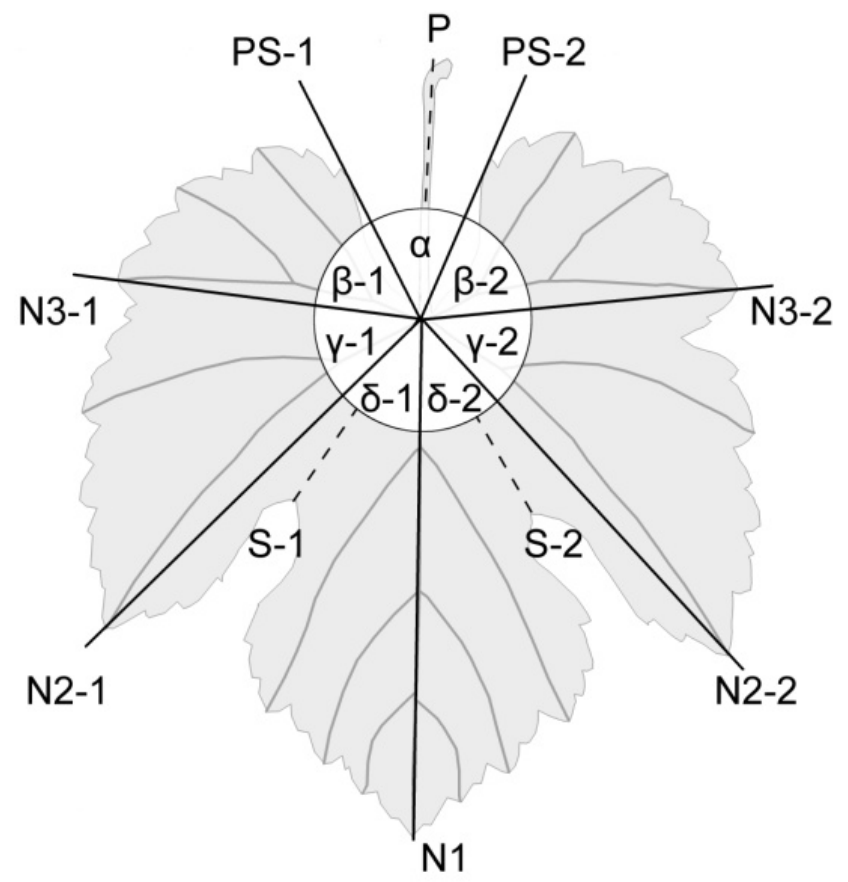

FIGURE 1

Grapevine (Vitis vinifera L.) leaf with indication of some ampelometric parameters.
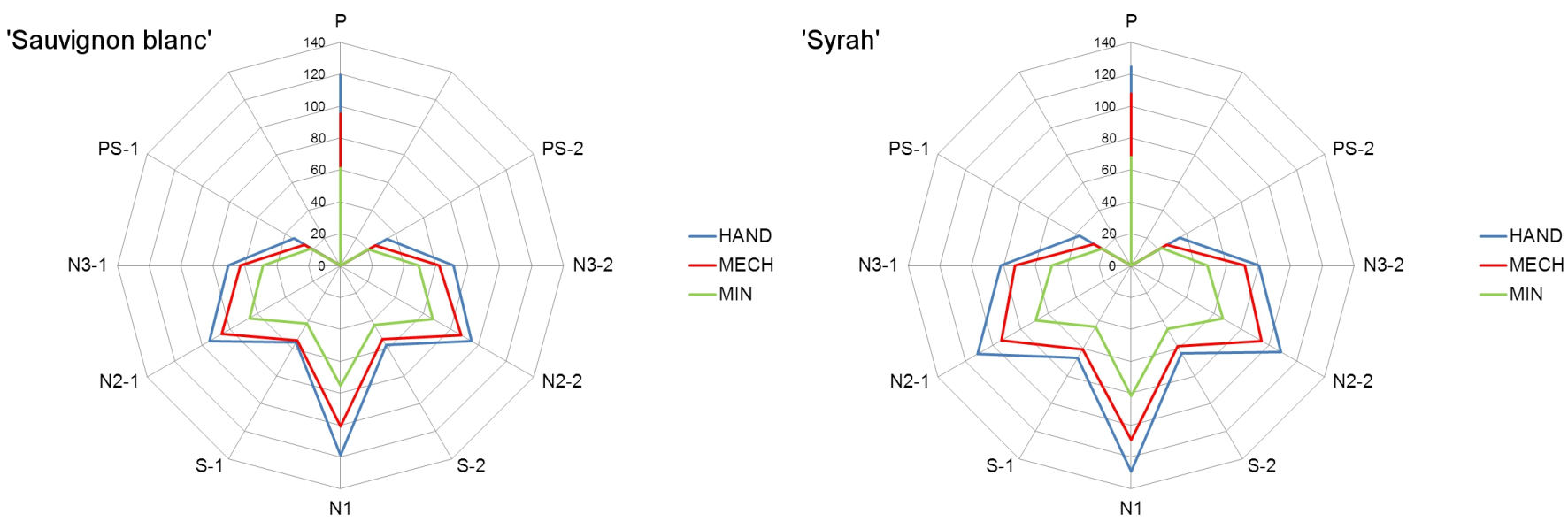

FIGURE 2

Graphic reconstruction from the average vein, petiole length and depths of sinuses data obtained from Vitis vinifera L. cv. 'Sauvignon blanc' (A) and 'Syrah' (B) vines with different bud load/shoot number. were obtained when correlation analyses were done for both cultivars separately (data not shown). These results indicated that the change in leaf properties is symmetrical.

\section{Depth of sinuses} except in the case of the MIN treatment, where sinuses were $21 \%$ to $33 \%$ deeper than those of the other two treatments $(\mathrm{p}>0,05)$. However, the ratio between the depth of the sinuses and the lengths of the veins (N2-1/S-1; N2-2/S-2) did not change significantly $(\mathrm{p}>0.05)$.

\section{Angles between the veins}

Angles between the veins proved to be the most stable. No significant differences were observed in the case of 'Syrah' ( $p>0,05)$. Angles between veins, viz. $\gamma-1, \gamma-2$ and $\alpha$ (opening of the petiole sinus) of 'Sauvignon blanc', were more sensitive with MIN than with HAND and MECH.

\section{Length of the petiole and ratio to the main vein}

Treatments had significant effects on the lengths of the petioles; 'Sauvignon blanc' was more sensitive to pruning method than 'Syrah'. For the MIN vines, the length of the petiole was $50 \%$ shorter than that of the HAND vines, and it was $30 \%$ shorter than that of the $\mathrm{MECH}$ vines. The ratio between the main vein and he petiole was almost 1:1 in the case of HAND for both cultivars. For the MIN vines, the length of the petiole decreased by almost $25 \%$ related to the length of the main vein.

\section{DISCUSSION}

The morphological description of the grapevine leaf has great importance, since other representative organs, such as bunches, can be examined only for a limited time. To obtain a reliable description of the lamina, the elasticity that may be induced by viticultural practices has to be investigated.

To estimate morphological variability caused by pruning technique, within-vineyard variability was examined first. It can be concluded that only a few characteristics in this sample set were stable. Almost all of the features "switched"
No significant changes in depth of sinuses were observed, 
TABLE 1

Ampelometric data for hand (HAND), mechanically (MECH) and minimally (MIN) pruned Vitis vinifera L. cv. 'Sauvignon blanc' and 'Syrah' vines, with the relevant O.I.V. coding.

\begin{tabular}{|c|c|c|c|c|c|c|c|c|c|c|}
\hline \multirow{3}{*}{$\begin{array}{l}\text { Charac } \\
\text { teristic }\end{array}$} & \multirow{3}{*}{$\begin{array}{l}\text { Unit/ } \\
\text { OIV } \\
\text { code }\end{array}$} & \multicolumn{9}{|c|}{ 'Sauvignon blanc' } \\
\hline & & \multicolumn{3}{|c|}{ HAND } & \multicolumn{3}{|c|}{ МЕСН } & \multicolumn{3}{|c|}{ MIN } \\
\hline & & Average & St. dev. & $\operatorname{Min} \rightarrow \operatorname{Max}$ & Average & St. dev. & $\operatorname{Min} \rightarrow \operatorname{Max}$ & Average & St. dev. & Min $\rightarrow$ Max \\
\hline SLA & $\mathrm{cm}^{2}$ & $184.19_{\mathrm{c}}$ & \pm 20.65 & $151.36 \rightarrow 214.26$ & $131.91_{b}$ & \pm 19.55 & $114.79 \rightarrow 176.56$ & $75.14_{a}$ & \pm 13.42 & $56.98 \rightarrow 96.82$ \\
\hline OIV No. & - & - & & - & - & & - & - & & - \\
\hline N1 & $\mathrm{mm}$ & $118.94_{\mathrm{c}}$ & \pm 9.08 & $106.02 \rightarrow 130.74$ & $100.98_{\mathrm{b}}$ & \pm 9.14 & $92.56 \rightarrow 123.8$ & $75.32 \mathrm{a}$ & \pm 5.89 & $67.72 \rightarrow 88.8$ \\
\hline OIV No. & 601 & 3 & & $3 \rightarrow 5$ & 3 & & $3 \rightarrow 5$ & 1 & & 1 \\
\hline $\mathbf{P}$ & $\mathrm{mm}$ & $119.48_{c}$ & \pm 15.96 & $101.92 \rightarrow 154.34$ & $95.02_{\mathrm{b}}$ & \pm 5.11 & $88.25 \rightarrow 102.96$ & $61.26_{\mathrm{a}}$ & \pm 11.14 & $47.86 \rightarrow 82.07$ \\
\hline OIV No. & - & - & & - & - & & - & - & & - \\
\hline $\mathbf{P} / \mathbf{N} 1$ & ratio & $1.00_{\mathrm{b}}$ & \pm 0.09 & $0.87 \rightarrow 1.23$ & $0.94_{\mathrm{ab}}$ & \pm 0.08 & $0.81 \rightarrow 1.1$ & $0.81_{\mathrm{a}}$ & \pm 0.13 & $0.66 \rightarrow 1.08$ \\
\hline OIV No. & 093 & 5 & & $3 \rightarrow 7$ & 5 & & $3 \rightarrow 5$ & 3 & & $1 \rightarrow 5$ \\
\hline N2-1 & $\mathrm{mm}$ & $94.97 \mathrm{~b}$ & \pm 6.01 & $83.34 \rightarrow 105.12$ & $87.55_{b}$ & \pm 8.43 & $80.14 \rightarrow 106.4$ & $66.76_{a}$ & \pm 5.62 & $58.49 \rightarrow 73.96$ \\
\hline OIV No. & 602 & 3 & & $3 \rightarrow 5$ & 3 & & $3 \rightarrow 5$ & 1 & & 1 \\
\hline $\mathrm{N} 2-2$ & $\mathrm{~mm}$ & $94.67_{b}$ & \pm 8.79 & $76.59 \rightarrow 104.29$ & $85.88_{b}$ & \pm 7.26 & $77.22 \rightarrow 97.51$ & $66.01_{\mathrm{a}}$ & \pm 6.84 & $56.37 \rightarrow 76.65$ \\
\hline OIV No. & 602 & 3 & & $3 \rightarrow 5$ & 3 & & $3 \rightarrow 5$ & 1 & & $1 \rightarrow 3$ \\
\hline S-1 & $\mathrm{mm}$ & $57.33_{\mathrm{b}}$ & \pm 7.80 & $40.1 \rightarrow 69.14$ & $53.11_{\mathrm{b}}$ & \pm 8.04 & $38.1 \rightarrow 62.1$ & $42.95 \mathrm{a}$ & \pm 5.60 & $35.5 \rightarrow 51.51$ \\
\hline OIV No.* & 605 & 3 & & $3 \rightarrow 5$ & 3 & & $1 \rightarrow 5$ & 3 & & $1 \rightarrow 3$ \\
\hline $\mathrm{S}-2$ & $\mathrm{~mm}$ & $55.69_{\mathrm{b}}$ & \pm 8.16 & $43.12 \rightarrow 66.25$ & $54.18_{\mathrm{b}}$ & \pm 4.53 & $49.5 \rightarrow 65.06$ & $41.95 \mathrm{a}$ & \pm 3.19 & $37.42 \rightarrow 46.77$ \\
\hline OIV No.* & 605 & 3 & & $3 \rightarrow 5$ & 3 & & $3 \rightarrow 5$ & 3 & & $1 \rightarrow 3$ \\
\hline N2-1/S-1 & ratio & $1.68_{\mathrm{a}}$ & \pm 0.23 & $1.44 \rightarrow 2.23$ & $1.67 \mathrm{a}$ & \pm 0.23 & $1.38 \rightarrow 2.10$ & $1.57_{\mathrm{a}}$ & \pm 0.24 & $1.29 \rightarrow 2.03$ \\
\hline OIV No. & $094 * *$ & 3 & & $3 \rightarrow 5$ & 3 & & $3 \rightarrow 5$ & 3 & & $3 \rightarrow 5$ \\
\hline $\mathrm{N} 2-2 / \mathrm{S}-2$ & ratio & $1.63_{\mathrm{a}}$ & \pm 0.23 & $1.21 \rightarrow 1.91$ & $1.59 \mathrm{a}$ & \pm 0.17 & $1.41 \rightarrow 1.86$ & $1.57_{\mathrm{a}}$ & \pm 0.16 & $1.36 \rightarrow 1.85$ \\
\hline OIV No. & $094 * *$ & 3 & & $3 \rightarrow 5$ & 3 & & $3 \rightarrow 5$ & 3 & & $3 \rightarrow 5$ \\
\hline N3-1 & $\mathrm{mm}$ & $70.79_{c}$ & \pm 5.41 & $59.65 \rightarrow 78.44$ & $62.15_{b}$ & \pm 6.66 & $52.71 \rightarrow 74.3$ & $49.12_{\mathrm{a}}$ & \pm 7.21 & $38.7 \rightarrow 59.8$ \\
\hline OIV No. & 603 & 5 & & $3 \rightarrow 5$ & 3 & & $3 \rightarrow 5$ & 3 & & $1 \rightarrow 3$ \\
\hline N3-2 & $\mathrm{mm}$ & $70.53_{c}$ & \pm 5.85 & $60.18 \rightarrow 79.14$ & $62.85_{\mathrm{b}}$ & \pm 6.58 & $54.33 \rightarrow 72.67$ & $48.51_{\mathrm{a}}$ & \pm 6.46 & $36.63 \rightarrow 58.52$ \\
\hline OIV No. & 603 & 5 & & $3 \rightarrow 5$ & 3 & & $3 \rightarrow 5$ & 3 & & $1 \rightarrow 3$ \\
\hline PS-1 & $\mathrm{mm}$ & $33.73_{\mathrm{b}}$ & \pm 3.99 & $28.45 \rightarrow 39.12$ & $26.21_{b}$ & \pm 4.72 & $20.39 \rightarrow 36.24$ & $21.50_{\mathrm{a}}$ & \pm 5.93 & $13.82 \rightarrow 29.51$ \\
\hline OIV No. & - & - & & - & - & & - & - & & - \\
\hline PS-2 & $\mathrm{mm}$ & $33.59_{c}$ & \pm 4.58 & $24.08 \rightarrow 38.95$ & $25.28_{\mathrm{b}}$ & \pm 3.34 & $21.6 \rightarrow 33.94$ & $20.12_{\mathrm{a}}$ & \pm 3.56 & $15.32 \rightarrow 26.13$ \\
\hline OIV No. & - & - & & - & - & & - & - & & - \\
\hline$\delta-1$ & degree & $43.54^{\circ}{ }_{\mathrm{a}}$ & \pm 8.68 & $30.61 \rightarrow 58.22$ & $37.03^{\circ}{ }_{a}$ & \pm 6.48 & $29.36 \rightarrow 46.89$ & $37.2^{\circ}{ }_{\mathrm{a}}$ & \pm 5.95 & $28.25 \rightarrow 47.52$ \\
\hline OIV No. & 607 & 3 & & $1 \rightarrow 7$ & 3 & & $1 \rightarrow 5$ & 3 & & $1 \rightarrow 5$ \\
\hline$\delta-2$ & degree & $41.06^{\circ}{ }_{a}$ & \pm 11.73 & $21.1 \rightarrow 59.55$ & $38.03^{\circ}{ }_{a}$ & \pm 5.69 & $26.69 \rightarrow 44.85$ & $36.82^{\circ}{ }_{\mathrm{a}}$ & \pm 8.04 & $24.56 \rightarrow 50.15$ \\
\hline OIV No. & 607 & 3 & & $1 \rightarrow 7$ & 3 & & $1 \rightarrow 3$ & 3 & & $1 \rightarrow 5$ \\
\hline$\gamma-1$ & degree & $62.91^{\circ}{ }_{b}$ & \pm 6.68 & $54.43 \rightarrow 72.79$ & $56.38^{\circ}{ }_{\mathrm{ab}}$ & \pm 9.55 & $39.06 \rightarrow 70.12$ & $51.48^{\circ}{ }_{a}$ & \pm 7.43 & $43.11 \rightarrow 64.24$ \\
\hline OIV No. & 608 & 7 & & $5 \rightarrow 9$ & 7 & & $3 \rightarrow 9$ & 5 & & $3 \rightarrow 7$ \\
\hline$\gamma-2$ & degree & $63.97^{\circ}$ & \pm 6.32 & $55.82 \rightarrow 72.03$ & $54.83^{\circ}$ & \pm 9.16 & $41.81 \rightarrow 66.8$ & $55.65^{\circ}{ }_{a b}$ & \pm 7.90 & $44.64 \rightarrow 68.75$ \\
\hline OIV No. & 608 & 7 & & $7 \rightarrow 9$ & 5 & & $3 \rightarrow 7$ & 5 & & $3 \rightarrow 7$ \\
\hline$\beta-1$ & degree & $78.46^{\circ}{ }_{a}$ & \pm 8.67 & $64.31 \rightarrow 90.18$ & $72.21^{\circ}$ & \pm 18.49 & $45.37 \rightarrow 98.31$ & $64.21_{\mathrm{a}}^{\circ}$ & \pm 11.60 & $38.15 \rightarrow 80.8$ \\
\hline OIV No. & 610 & 9 & & $7 \rightarrow 9$ & 9 & & $3 \rightarrow 9$ & 7 & & $3 \rightarrow 9$ \\
\hline$\beta-2$ & degree & $74.35^{\circ}{ }_{\mathrm{a}}$ & \pm 15.43 & $55.63 \rightarrow 102.53$ & $78.00^{\circ}{ }_{a}$ & \pm 15.87 & $51.83 \rightarrow 101.06$ & $66.81^{\circ}$ & \pm 13.92 & $43.11 \rightarrow 84.16$ \\
\hline OIV No. & 610 & 9 & & $5 \rightarrow 9$ & 9 & & $5 \rightarrow 9$ & 7 & & $3 \rightarrow 9$ \\
\hline$\alpha$ & degree & $-5.53^{\circ}{ }_{\mathrm{a}}$ & \pm 19.21 & $-27.06 \rightarrow 33.14$ & $22.61^{\circ}{ }_{b}$ & \pm 17.73 & $0.72 \rightarrow 55.36$ & $48.11^{\circ}{ }_{\mathrm{c}}$ & \pm 22.21 & $19.52 \rightarrow 74.51$ \\
\hline OIV No. & $618^{*}$ & - & & - & - & & - & - & & - \\
\hline PS1-PS2 & $\mathrm{mm}$ & $+3.81_{\mathrm{a}}$ & \pm 11.26 & $+17.95 \rightarrow-15.59$ & $-10.14_{b}$ & \pm 7.03 & $-0.76 \rightarrow-19.71$ & $-16.40_{b}$ & \pm 6.69 & $-7.52 \rightarrow-29.22$ \\
\hline OIV No. & $618^{*}$ & 5 & & $3 \rightarrow 7$ & 3 & & $3 \rightarrow 5$ & 3 & & $1 \rightarrow 5$ \\
\hline
\end{tabular}

Morphological characteristics signed with * $* *$ were estimated with modifications compared to O.I.V. (2009a) descriptor list. Different letters indicate significant differences at the $5 \%$ level. 
TABLE 1 (CONTINUED).

Ampelometric data for hand (HAND), mechanically (MECH) and minimally (MIN) pruned Vitis vinifera L. cv. 'Sauvignon blanc' and 'Syrah' vines, with the relevant O.I.V. coding.

\begin{tabular}{|c|c|c|c|c|c|c|c|c|c|c|}
\hline \multirow{3}{*}{$\begin{array}{l}\text { Charac } \\
\text { teristic }\end{array}$} & \multirow{3}{*}{$\begin{array}{l}\text { Unit/ } \\
\text { OIV } \\
\text { code }\end{array}$} & \multicolumn{9}{|c|}{ 'Syrah' } \\
\hline & & \multicolumn{3}{|c|}{ HAND } & \multicolumn{3}{|c|}{ МECH } & \multicolumn{3}{|c|}{ MIN } \\
\hline & & Average & St. dev. & $\operatorname{Min} \rightarrow \operatorname{Max}$ & Average & St. dev. & $\operatorname{Min} \rightarrow \operatorname{Max}$ & Average & St. dev. & $\operatorname{Min} \rightarrow \operatorname{Max}$ \\
\hline SLA & $\mathrm{cm}^{2}$ & $231.19_{c}$ & \pm 56.75 & $158.52 \rightarrow 322.75$ & $160.84_{b}$ & \pm 20.39 & $118.83 \rightarrow 194.58$ & $88.61_{a}$ & \pm 34.96 & $56.81 \rightarrow 165.75$ \\
\hline OIV No. & - & - & & - & - & & - & - & & - \\
\hline N1 & $\mathrm{mm}$ & $128.98_{c}$ & \pm 22.52 & $93.93 \rightarrow 167.61$ & $109.30_{\mathrm{b}}$ & \pm 9.10 & $94.46 \rightarrow 121.68$ & $81.96_{a}$ & \pm 11.49 & $62.85 \rightarrow 98.94$ \\
\hline OIV No. & 601 & 5 & & $3 \rightarrow 7$ & 3 & & $3 \rightarrow 5$ & 1 & & $1 \rightarrow 3$ \\
\hline $\mathbf{P}$ & $\mathrm{mm}$ & $124.65_{b}$ & \pm 20.80 & $98.64 \rightarrow 165.67$ & $107.58_{\mathrm{b}}$ & \pm 11.65 & $89.11 \rightarrow 119.48$ & $68.07 \mathrm{a}$ & \pm 15.03 & 53.74105 .69 \\
\hline OIV No. & - & - & & - & - & & - & - & & - \\
\hline $\mathbf{P} / \mathbf{N} 1$ & ratio & $0.97_{\mathrm{b}}$ & \pm 0.14 & $0.65 \rightarrow 1.12$ & $0.98_{\mathrm{b}}$ & \pm 0.10 & $0.82 \rightarrow 1.11$ & $0.82_{a}$ & \pm 0.11 & $0.69 \rightarrow 1.11$ \\
\hline OIV No. & 093 & 5 & & $1 \rightarrow 5$ & 5 & & $3 \rightarrow 5$ & 3 & & $1 \rightarrow 5$ \\
\hline N2-1 & $\mathrm{mm}$ & $108.76_{b}$ & \pm 16.04 & $78.28 \rightarrow 130.98$ & $94.71_{b}$ & \pm 5.59 & $88.05 \rightarrow 106.85$ & $66.29_{\mathrm{a}}$ & \pm 9.59 & $54.42 \rightarrow 84.01$ \\
\hline OIV No. & 602 & 5 & & $3 \rightarrow 7$ & 3 & & $3 \rightarrow 5$ & 1 & & $1 \rightarrow 3$ \\
\hline N2-2 & $\mathrm{mm}$ & $111.02_{\mathrm{c}}$ & \pm 18.25 & $89.09 \rightarrow 152.6$ & $93.68_{\mathrm{b}}$ & \pm 11.40 & $75.58 \rightarrow 112.8$ & $68.97_{\mathrm{a}}$ & \pm 16.88 & $49.48 \rightarrow 102.96$ \\
\hline OIV No. & 602 & 5 & & $3 \rightarrow 9$ & 3 & & $3 \rightarrow 5$ & 1 & & $1 \rightarrow 5$ \\
\hline S-1 & $\mathrm{mm}$ & $63.57_{b}$ & \pm 11.46 & $46.88 \rightarrow 83.41$ & $58.20_{\mathrm{b}}$ & \pm 7.51 & $46.96 \rightarrow 68.97$ & $45.95_{\mathrm{a}}$ & \pm 9.20 & $35.29 \rightarrow 64.85$ \\
\hline OIV No.* & 605 & 5 & & $3 \rightarrow 7$ & 3 & & $3 \rightarrow 5$ & 3 & & $1 \rightarrow 5$ \\
\hline S-2 & $\mathrm{mm}$ & $66.68_{b}$ & \pm 17.03 & $40.4 \rightarrow 105.59$ & $60.60_{b}$ & \pm 7.96 & $50.2 \rightarrow 74.42$ & 44.6 & \pm 13.35 & $29.14 \rightarrow 74.95$ \\
\hline OIV No.* & 605 & 5 & & $3 \rightarrow 9$ & 5 & & $3 \rightarrow 5$ & 3 & & $1 \rightarrow 5$ \\
\hline N2-1/S-1 & ratio & $1.74_{\mathrm{a}}$ & \pm 0.38 & $1.22 \rightarrow 2.46$ & $1.64_{\mathrm{a}}$ & \pm 0.18 & $1.34 \rightarrow 1.94$ & $1.45_{\mathrm{a}}$ & \pm 0.13 & $1.29 \rightarrow 1.66$ \\
\hline OIV No. & $094 * *$ & 3 & & $3 \rightarrow 5$ & 3 & & $3 \rightarrow 5$ & 3 & & 3 \\
\hline $\mathrm{N} 2-2 / \mathrm{S}-2$ & ratio & $1.71_{\mathrm{a}}$ & \pm 0.26 & $1.44 \rightarrow 2.20$ & $1.55_{\mathrm{a}}$ & \pm 0.13 & $1.33 \rightarrow 1.75$ & $1.57_{\mathrm{a}}$ & \pm 0.21 & $1.08 \rightarrow 1.83$ \\
\hline OIV No. & $094 * *$ & 3 & & $3 \rightarrow 5$ & 3 & & $3 \rightarrow 5$ & 3 & & $1 \rightarrow 5$ \\
\hline N3-1 & $\mathrm{mm}$ & $80.10_{b}$ & \pm 8.05 & $68.75 \rightarrow 89.36$ & $71.35_{b}$ & \pm 6.44 & $57 \rightarrow 79.53$ & $47.83_{\mathrm{a}}$ & \pm 11.60 & $32.96 \rightarrow 68.32$ \\
\hline OIV No. & 603 & 5 & & $5 \rightarrow 7$ & 5 & & $3 \rightarrow 5$ & 3 & & $1 \rightarrow 5$ \\
\hline N3-2 & $\mathrm{mm}$ & $81.62_{b}$ & \pm 9.10 & $68.51 \rightarrow 92.29$ & $72.91_{b}$ & \pm 9.58 & $58.39 \rightarrow 91.22$ & $49.68_{a}$ & \pm 12.02 & $37.89 \rightarrow 75.3$ \\
\hline OIV No. & 603 & 5 & & $5 \rightarrow 7$ & 5 & & $3 \rightarrow 7$ & 3 & & $1 \rightarrow 5$ \\
\hline PS-1 & $\mathrm{mm}$ & $37.45_{b}$ & \pm 8.95 & $23.72 \rightarrow 56.44$ & $27.12_{\mathrm{a}}$ & \pm 4.46 & $20.99 \rightarrow 37.37$ & $20.74_{a}$ & \pm 5.94 & $11.57 \rightarrow 33.12$ \\
\hline OIV No. & - & - & & - & - & & - & - & & - \\
\hline PS-2 & $\mathrm{mm}$ & $35.13_{b}$ & \pm 6.78 & $25.28 \rightarrow 44.75$ & $25.82_{\mathrm{a}}$ & \pm 7.61 & $16.68 \rightarrow 37.16$ & $22.13_{\mathrm{a}}$ & \pm 6.63 & $13.71 \rightarrow 32$ \\
\hline OIV No. & - & - & & - & - & & - & - & & - \\
\hline$\delta-1$ & degree & $45.19^{\circ}{ }_{a}$ & \pm 5.93 & $35.48 \rightarrow 53.01$ & $38.78^{\circ}$ & \pm 10.17 & $16.21 \rightarrow 48.67$ & $41.53^{\circ}$ & \pm 6.69 & $29.69 \rightarrow 51.32$ \\
\hline OIV No. & 607 & 3 & & $3 \rightarrow 5$ & 3 & & $1 \rightarrow 5$ & 3 & & $1 \rightarrow 5$ \\
\hline$\delta-2$ & degree & $45.57^{\circ}$ & \pm 9.39 & $28.33 \rightarrow 62.31$ & $43.7^{\circ}{ }_{a}$ & \pm 5.84 & $34.76 \rightarrow 51.13$ & $42.27^{\circ}$ & \pm 8.24 & $29.34 \rightarrow 51.25$ \\
\hline OIV No. & 607 & 3 & & $1 \rightarrow 7$ & 3 & & $3 \rightarrow 5$ & 3 & & $1 \rightarrow 5$ \\
\hline$\gamma-1$ & degree & $60.62^{\circ}$ & \pm 5.13 & $54.87 \rightarrow 73.17$ & $56.09^{\circ}$ & \pm 7.13 & $46.54 \rightarrow 69.48$ & $57.07^{\circ}$ & \pm 8.99 & $40.15 \rightarrow 72.31$ \\
\hline OIV No. & 608 & 7 & & $5 \rightarrow 9$ & 7 & & $5 \rightarrow 7$ & 7 & & $3 \rightarrow 9$ \\
\hline$\gamma-2$ & degree & $62.11^{\circ}$ & \pm 3.79 & $55.98 \rightarrow 70.45$ & $54.6^{\circ}{ }_{a}$ & \pm 8.89 & $37.97 \rightarrow 66.59$ & $58.89^{\circ}$ & \pm 7.02 & $49.9 \rightarrow 67.58$ \\
\hline OIV No. & 608 & 7 & & $5 \rightarrow 9$ & 5 & & $3 \rightarrow 7$ & 7 & & $5 \rightarrow 7$ \\
\hline$\beta-1$ & degree & $72.92^{\circ}{ }_{a}$ & \pm 11.15 & $58.27 \rightarrow 94.22$ & $77.2^{\circ}{ }_{\mathrm{a}}$ & \pm 11.51 & $59.34 \rightarrow 97.14$ & $70.53^{\circ}$ & \pm 17.43 & $51.19 \rightarrow 101.76$ \\
\hline OIV No. & 610 & 9 & & $7 \rightarrow 9$ & 9 & & $7 \rightarrow 9$ & 9 & & $5 \rightarrow 9$ \\
\hline$\beta-2$ & degree & $61.39^{\circ}{ }_{\mathrm{a}}$ & \pm 10.55 & $48.64-86.68$ & $81.16^{\circ}$ & \pm 8.91 & $62.12 \rightarrow 91.07$ & $66.15^{\circ}$ & \pm 13.29 & $42.77 \rightarrow 79.88$ \\
\hline OIV No. & 610 & 7 & & $5 \rightarrow 9$ & 9 & & $7 \rightarrow 9$ & 7 & & $3 \rightarrow 9$ \\
\hline$\alpha$ & degree & $-0.44^{\circ}{ }_{a}$ & \pm 25.06 & $-39.25 \rightarrow 28.99$ & $9.33^{\circ}{ }_{b}$ & \pm 9.86 & $0.33 \rightarrow 31.04$ & $23.19^{\circ}{ }_{\mathrm{c}}$ & \pm 15.95 & $2.31 \rightarrow 54.62$ \\
\hline OIV No. & $618^{*}$ & - & & - & - & & - & - & & - \\
\hline PS1-PS2 & $\mathrm{mm}$ & $+0.83_{\mathrm{a}}$ & \pm 16.45 & $+29.25 \rightarrow-15.86$ & $-6.76_{b}$ & \pm 4.02 & $-0.76 \rightarrow-13.35$ & $-8.54_{b}$ & \pm 5.46 & $-1.73 \rightarrow-17.3$ \\
\hline OIV No. & $618^{*}$ & 5 & & $3 \rightarrow 7$ & 5 & & $3 \rightarrow 5$ & 5 & & $3 \rightarrow 5$ \\
\hline
\end{tabular}

Morphological characteristics signed with *, ** were estimated with modifications compared to O.I.V. (2009a) descriptor list. Different letters indicate significant differences at the $5 \%$ level. 
one to four categories in the O.I.V. classification, within one cultivar under the same treatment. The lowest withinvineyard variability was observed in the depths of upper sinuses in both cultivars, while the highest variability occurred in the case of angles between the veins and the opening of the petiole sinus. According to the data of the 18 O.I.V. descriptors monitored in the six sample sets, $98 \%$ of the characteristics proved to be variable and only $2 \%$ were stable.

In this study, the number of shoots correlated negatively with SLA. This can be explained by the increasing number of shoots per root system that decreased the vigour per shoot. The HAND and MECH treatments had almost the same effect on the leaves, while the MIN treatment changed the SLA and lengths of the veins significantly. According to Niinemets and Fleck (2002), not only the size of the lamina is varied by modified conditions such as radiation, but the petiole properties are also affected. In this study, petiole length was decreased significantly by the MIN treatment, both in absolute value and relative to the main vein. The results parallel the observations reported by Miller et al. (1997), Poni et al. (2000) and Intrieri et al. (2001), namely that the SLA is sensitive to bud load and microclimate.

On the basis of change in bud load, the leaf characteristics of 'Syrah' and 'Sauvignon blanc' could be divided into two groups, namely variable and stable. Ortiz et al. (2004) grouped (leaf) morphological characteristics into three groups in their sample set. Symbols are used to compare those characteristics with the O.I.V. (2009a) descriptor list and our present study (\#: OIV; \#\#: present study). The following characteristics were grouped:

- non-discriminant characteristics with the same expression in all samples (not listed);

- discriminant characteristics: $\mathrm{W} \times \mathrm{H}$; L2/L $\left(\mathrm{N} 3 / \mathrm{N} 1^{\#}\right)$; $\mathrm{L} 3 / \mathrm{L}\left(\mathrm{N} 4 / \mathrm{N}^{\#}\right), \mathrm{L} 4 / \mathrm{L}\left(\mathrm{N} 5 / \mathrm{N1}^{\#}\right)$; d (opening of the petiole sinus, PS1-PS2); $\wedge_{a}+\wedge_{b}$ (O.I.V. $607+$ O.I.V. 608\#; $\left.\delta+\gamma^{\# \prime}\right) ; \wedge_{\mathrm{a}}+\wedge_{\mathrm{b}}+\wedge_{\mathrm{c}}$ (O.I.V. $607+$ O.I.V. $608+$ O.I.V. $\left.609^{\#}\right) ; \wedge_{\mathrm{a}}+\wedge_{\mathrm{b}}+\wedge_{\mathrm{t}}$ (O.I.V. $607+$ O.I.V. $608+$ O.I.V. $\left.610^{\# ;} \delta+\gamma+\beta^{\# \#}\right) ; \wedge \mathrm{a}+\wedge \mathrm{t}$ (O.I.V. $607+$ O.I.V. $610^{\#} ; \delta+\beta^{\# \#)}$;

- stable or objective characteristics appropriate for clear identification: shape of blade (O.I.V. 067), number of lobes (O.I.V. 068), anthocyanin coloration of the main veins on the upper side of the blade (O.I.V. 070), presence of teeth in the petiole sinus (O.I.V. 081-1), naked petiole sinus (O.I.V. 081-2), shape of upper leaf sinuses (O.I.V. 082), shape of the base of the upper leaf sinuses (O.I.V. 083-1), presence of teeth at the base of the upper leaf sinuses (O.I.V. 083-2) and density of erect hairs on the petiole (O.I.V. 091).

According to the classification of the morphological characteristics reported by Ortiz et al. (2004), ampelographic patterns used in our present study could be classified into discriminant characteristics with two sub-groups: stable and variable. It has to be mentioned that the grouping of variables as "stable" or "variable" depends on the sample set, the environmental circumstances and the treatment applied.

The results proved that stable characteristics (angles between the veins, depth of sinuses) could serve as descriptors, whereas variable properties (SLA and length of veins and petioles) may depend on cultivation practices. This was supported by metrical and statistical analyses, thus providing objective conclusions on the usefulness of leaf features in cultivar identification and on the impact of cultivation.

This study provided a metrical description of the grapevine leaf and its variability, as affected by cultivation and ecological parameters. We have shown that the morphological identification of the grapevine according to the leaf should be clarified with a consideration and clear indication of at least the pruning method and bud load. It is proposed that cultivation practices should be detailed thoroughly whenever a morphological identification of the grapevine is attempted.

\section{CONCLUSIONS}

'Sauvignon blanc' and 'Syrah' leaves collected from minimally pruned, mechanically pruned and hand-pruned vines were compared using 22 ampelometric features. According to the analysis of within-vineyard variability, it can be concluded that foliometric characteristics of both of the cultivars were highly variable within treatments. Further experimentation on a large scale is required to clarify the impact of within-vineyard variability on foliometric characteristics. In the case of the ampelometric variability caused by pruning level/bud load, it can be concluded that the morphological characteristics of the leaves can be divided into two groups, viz. stable (angles between the veins, depths of sinuses) and variable (single leaf area and lengths of veins and petioles). Stable characteristics could serve as descriptors of varietal identification, whereas variable properties may depend on cultivation practices. Ampelometric (foliometric) analyses are objective and highly valuable in the assessment of genetically determined morphological characteristics influenced by environmental factors and cultivation practices.

\section{LITERATURE CITED}

Alessandri, S., Vignozzi, N. \& Vignini, A., 1996. AmpeloCADs (Ampelographic Computer-Aided Digitizing System). An integrated system to digitize and process biometrical data from Vitis spp. leaves. Am. J. Enol. Vitic. 47(3), 257-267.

Archer, E. \& Van Schalkwyk, D., 2007. The effect of alternative pruning methods on viticultural and oenological performance of some wine grape varieties. S. Afr. J. Enol. Vitic. 28(2), 107-139.

Beslic, Z., Todic, S. \& Tesic, D., 2010. Validation of non-destructive methodology of grapevine leaf area estimation on cv. Blauerfränkisch (Vitis vinifera L.). S. Afr. J. Enol. Vitic. 31(1), 22-25.

Bodor, P., Baranyai, L., Bálo, B., Tóth, E., Strever, A., Hunter, J.J. \& Bisztray, Gy.D., 2012. GRA.LE.D. (GRApevine LEaf Digitalization) software for the detection and graphic reconstruction of ampelometric differences between Vitis leaves. S. Afr. J. Enol. Vitic. 33(1), 1-6.

Box, G.E.P. \& Cox, D.R., 1964. An analysis of transformations. J. Royal Stat. Soc. Series B 26(2), 211-252.

Bramley, R.G.V. \& Hamilton, R.P., 2004. Understanding variability in winegrape production systems. 1. Within vineyard variation in yield over several vintages. Aust. J. Grape Wine Res. 10, 32-45. 
Cangi, R. \& Kiliç, D. 2011. Effects of bud loading levels and nitrogen doses on yield, physical and chemical properties of brined grape-leaves. Afr. J. Biotech. 10(57), 12195-12201.

Cervera, M.T., Rodriguez, I., Cabenaz, J.A., Chavez, J., Martínez-Zapater, J.M. \& Cabello, F., 2001. Morphological and molecular characterization of grapevine accessions known as Albillo. Am. J. Enol. Vitic. 52(2), 127-135. Clingeleffer, P.R., 1984. Production and growth of minimal pruned Sultana vines. Vitis 23, 42-54.

Clingeleffer, P.R. \& Krake, L.R., 1992. Response of Cabernet franc grapevines to minimal pruning and virus infection. Am. J. Enol. Vitic. 43(1), $31-37$

D’Agostino, R.B., Belanger, A. \& D'Agostino, R.B., Jr., 1990. A suggestion for using powerful and informative test of normality. The Am. Stat. 44(4), 316-321.

Downton, W.J.S. \& Grant, W.J.R., 1992. Photosynthetic physiology of spur pruned and minimal pruned grapevine. Aust. J. Plant Physiol. 19, 309-316.

Everitt, B.S. \& Dunn, G., 1991. Applied multivariate data analysis. Edward Arnold, London.

Ferree, D.C. \& Streeter, J.G., 2004. Response of container-grown grapevines to soil compaction. HortScience 39(6), 1250-1254.

Fisarakis, I., Chartzoulakis, K. \& Stavrakas, D., 2001. Response of Sultana vines $(V$. vinifera $\mathrm{L}$.) on six rootstocks to $\mathrm{NaCl}$ salinity exposure and recovery. Agr. Water Management 51, 13-27.

Gago, P., Santiago, J.L., Boso, S., Alonso-Villaverde, V. \& Martinez, M.C., 2009. Grapevine (Vitis vinifera L.). Old varieties are reflected in work of art. Econom. Bot. 63(1), 67-77.

Galet, P., 1956. Cepages et Vignobles de France. Tome 1. Rue VieilleIntendance, Montpellier.

González, M.F., Martínez, J. \& Mena, A., 2007. Morphological and molecular characterization of grapevine known as Moravia/o (Vitis vinifera L.). Am. J. Enol. Vitic. 58(4), 544-547.

Goussard, P.G., 2008. Grape cultivars for wine production in South Africa. Cheviot Publishing, Cape Town, South Africa. 166.

Hunter, J.J., Archer, E. \& Volschenk, C.G., 2010. Vineyard management for environment valorisation. In: Proc. $8^{\text {th }}$ Int. Zoning Congress, Soave, Italy (CRA-VIT, Conegliano). June 2010. pp. 7.3 - 7.15.

Intrieri, C., Filippetti, I., Allegro, G.V., Pastore, C. \& Colucci, E., 2011. The semi-minimal-pruned hedge: a novel mechanized grapevine training system. Am J. Enol. Vitic. 62(3), 312-318.

Intrieri, C., Poni, S., Lia, G. \& Campo, M.G., 2001. Vine performance and leaf physiology of conventionally and minimal pruned Sangiovese grapevine. Vitis 40(3), 123-130.

Kondou, H., Kitamura, H., Nishikawa, Y., Motonaga, Y. \& Hashimoto, A., 2002. Shape evaluation by digital camera for grape leaf. Proc. Third Asian Conf. for Inf. Tech. in Agric., October 2002. Beijing, China. pp. 586 - 590.

Krstic, M., Kelly, G., Hanah, R. \& Clingeleffer, P., 2005. Manipulating grape composition and wine quality through the use of rootstock. Grapevine rootstocks: current use, research, and application. Proceedings of the 2005 Rootstock Symposium, February 2005. Osage Beach, Missouri, USA. pp. $34-46$.

Martinez, M.C. \& Mantilla, J.L.G., 1995. Morphological and yield comparison between Vitis vinifera L. cv. Albariňo grown from cuttings and from in vitro propagation. Am. J. Enol. Vitic. 46(2), 195-203.

Maul, E., Sudharma, K.N., Kecke, S., Marx, G., Müller, C., Audeguin, L., Boselli, M., Boursiquot, J.M., Bucchetti, B., Cabello, F., Carraro, F., Crespan, M., De Andrés, M.T., Dias, J.E., Ekhvaia, J., Gaforio, L., Gardiman, M., Grando, M.S., Gyropoulos, D., Jandurova, O., Kiss, E.,
Kontic, J., Kozma, P., Lacombe, T., Laucou, V., Legrand, D., Maghradze, D., Marinoni, D., Maletic, E., Moreira Maia, F., Muñoz, G., Nakhutsrishvili, G., Pijic, I., Peterlunger, E., Pitsoli, D., Pospisilova, D., Preiner, D., Raimondi, S., Regner, F., Savin, G., Savvides, S., Schneider, A., Sereno, C., Simon, S., Staraz, M., Zulini, L., Bacilieri, R., This, P., 2012. The European Vitis Database (www.eu-vitis.de): a technical innovation through an online uploading and interactive modification system. Vitis 51(2), 79-85.

Miller, D.P., Howell, G.S. \& Flore, J.A., 1997. Influence of shoot number and crop load on potted Chambourcin grapevine. II. Whole-vines vs. single leaf photosynthesis. Vitis 36(3), 109-114.

Mullins, M.G., Bouquet, A. \& Williams, L.E., 2003. Biology of the grapevine. Cambridge University Press, Cambridge.

Németh, M. 1966. Borszőlőfajták határozókulcsa. Mezőgazdasági Kiadó, Budapest.

Németh, M. 1967. Ampelográfiai album. Termesztett borszőlőfajták 1. Mezőgazdasági Kiadó, Budapest.

Németh, M. 1970. Ampelográfiai album. Termesztett borszőlőfajták 2. Mezőgazdasági Kiadó, Budapest.

Niinemets, Ü. \& Fleck, S., 2002. Petiole mechanics, leaf inclination, morphology, and investment in support in relation to light availability in the canopy of Liriodendron tulipifera. Oecologia 132, 21-33.

O.I.V., 2009a $\left(2^{\text {nd }}\right.$ ed). OIV descriptor list for grape varieties and Vitis species. O.I.V. 18, rue d'Aguesseau - 75008 Paris.

O.I.V., 2009b. Description of world vine varieties. O.I.V. 18, rue d'Aguesseau - 75008 Paris. 560.

Ortiz, J.M., Martín, J.P., Borrego, J., Chávez, J., Rodríguez, I., Muňoz, G. \& Cabello, F., 2004. Molecular and morphological characterization of a Vitis gene bank for the establishment of a base collection. Gen. Res. Crop Evol. $51,403-409$.

Pliny the Elder. The natural history (eds. J. Bostock \& H.T. Riley, Esq., B.A. 1855). Book XIV. The nature of the vine. Its mode of frutification. Chapter 4. (2) Ninety-one varieties of the vine.

Poni, S., Intrieri, C. \& Magnanini, E., 2000. Seasonal growth and gas exchange of conventional and minimally pruned Chardonnay canopies. Vitis 39(1), 13-18.

Reynolds, A.G. \& Naylor, A.P., 1994. 'Pinot noir' and 'Riesling' grapevines respond to water stress duration and soil water capacity. Hort. Sci. 29(12), 1505-1510.

Rolley, L., Iland, P., Hart, A., Morath, P., Rouse, E., Blackman, J. \& Scollary, G., 2007. Managing vineyard variability for a targeted wine outcome. Final report to Grape and Wine Research \& Development Corporation. Nat. Wine Grape Ind. Centre. p . 77.

Schreiner, R.P., Lee, J. \& Skinkis, P.A., 2012. N, P, and K supply to Pinot noir grapevines: impact on vine nutrient status, growth, physiology and yield. Am. J. Enol. Vitic. doi:10.5344/ajev.2012.12064

Sefc, K.M., Lefort, F., Grando, M.S., Scott, K.D., Steinkellner, H. \& Thomas, M.R., 2001. Microsatellite markers for grapevine: a state of the art. In: Roubelakis-Angelakis, K.A. (ed), 2001. Molecular Biology Biotechnology of Grapevine, Kluwer Academic Publishers. The Netherlands.

Soldavini, C., Stefanini, M., Dallaserra, M., Policarpo, M. \& Schneider, A., 2009. SuperAmpelo, a software for ampelometric and ampelographic descriptions in Vitis. ISHS Acta Horticulturae 827. IX. Int. Conf. on Grape Genetics and Breeding. May 2009. Udine, Italy.

Sommer, K. J., Clingeleffer, P. R., 1993. Comparison of leaf area development, leaf physiology, berry maturation, juice quality and fruit yield of minimal and cane pruned Cabernet Sauvignon grapevines. Proc. 2nd N. Shaulis Symp. on Pruning Mechanization and Crop Control, July 13-14, 14-19. Fredonia, NewYork, USA. 
Sommer, K.J., Clingeleffer, P.R. \& Shulman, Y., 1995. Comparative study of vine morphology, growth, and canopy development in cane-pruned and minimal-pruned Sultana. Aust. J. E. Agr. 35, 265-273.

Viala, P. \& Vermorel, V., 1905. Ampélographie. Masson et Cie, Éditeurs, Paris.
Wolf, S. D., Silk, W. K., Plant, R. E., 1986. Quantitative Patterns of Leaf Expansion. Comparison of Normal and Malformed Leaf Growth in Vitis vinifera cv. Ruby Red. Am. J. Bot. 73 (6): 832-846.

Zulini, L., Fabro, E. \& Peterlunger, E. 2005. Characterization of the grapevine cultivar Picolit by means of morphological descriptors and molecular markers. Vitis 44(1), 35-38. 